\title{
How Do We Decide Which of Two Case Formulations Is Correct? Commentary on Westerman and Critchfield et al.
}

\author{
STANLEY B. MESSER ${ }^{\mathrm{a}, \mathrm{b}}$
}

${ }^{a}$ Graduate School of Applied and Professional Psychology, Rutgers University-New Brunswick, NJ

${ }^{\mathrm{b}}$ Correspondence regarding this article should be sent to: Stanley B. Messer, 324 Raritan Avenue

Highland Park, NJ 08904.

Email: smesser@gsapp.rutgers.edu

\begin{abstract}
This commentary takes a meta-view of the articles in this module by Westerman (2021a), and by Critchfield, Dobner-Pereira and Stucker (2021a), which offer two overlapping but also different formulations of the same case. It raises the question of whether there is only one true formulation of a clinical case (correspondence theory), or whether any one of several would qualify as accurate (coherence theory). A third alternative is that the truth-value of a formulation is a function of its ability to predict which therapist interventions will most help the client (pragmatic theory). A study is described in which the relative accuracy of two different formulations of the same case was put to the test in predicting which therapist interventions led to client progress. I propose that the current authors compare the pragmatic value of their formulations in a similar manner.
\end{abstract}

Keywords: comparing case formulations; truth-value of clinical formulations; correspondence, coherence and pragmatic theories of truth; Interpersonal Defense Theory; Interpersonal Reconstructive Theory (IRT); case study; clinical case study

There is an anecdote about a husband and wife who come separately to see a rabbi, each complaining of spouse abuse. Each partner wants the rabbi to adjudicate the matter and admonish and punish their spouse. In both instances, the rabbi strokes his beard and says to the petitioner that he or she has a good case and is right to seek admonishment and punishment of their spouse. A junior rabbi, who witnesses both pleadings, says to the rabbi that surely they are not both right. The rabbi responds: Yes, you are also right.

When I read a description of a well-reasoned and well-written formulation of a case, as in the case of Sharon presented below by Westerman, my reaction is to think, well, yes, he has got it right. Then I read another well reasoned and well-written but different formulation of the same case, as presented below by Critchfield, Dobner-Pereira and Stucker, I think, why, yes, they have also got it right. But then I ask myself (or the reader may ask), how can they both be right and I would say, yes, you are right, too--or maybe you are wrong in thinking that they can't both be right. 
Because this module includes extensive commentary by the authors on each others' paper, I will offer a meta-commentary, by which I mean that I will not focus on the merits of these two specific approaches to clinical material-Interpersonal Defense Theory (IDT) and Interpersonal Reconstructive Therapy (IRT)-- or discuss the specifics of the case of Sharon, but rather highlight a larger dilemma that the papers and commentaries bring to the fore. The dilemma is this: We have one case and two formulations that, while overlapping to some extent, are also quite different and lead to different interventions. In his commentary, Westerman emphasizes the differences between IDT and IRT whereas Critchfield et al. emphasize what they have in common. How are we to think about this not-so-unusual situation in which two different theories make some claim upon the truth and accuracy of the case formulations they lead to and the value of the interventions that follow from them?

There are varying solutions to this dilemma. We can ask whether, when it comes to case formulations, we are talking about needing to demonstrate what is known as historical truth, or is it narrative truth that we are dealing with (e.g., Spence, 1982)? To explain: Historical truth means that there is one correct formulation for a case and other formulations are wrong because they don't correspond correctly with the facts of the case, including the historical, developmental background. This is the correspondence theory of truth. Within this framework, knowledge of objects and events is gained through observation of things as they are, independent of the theories of the observer. This is called realism and it assumes a world and mental events that have their own natures quite apart from our perceptions of them. Within this view, to the extent that the IDT and IRT formulations differ, they can't both be right.

The alternative to the correspondence theory is what is known as the coherence theory of truth. From this perspective, case formulations are narratives and there is always more than one way to construct such a narrative. This is a form of idealism, which posits that clinical cases take on meaning by virtue of the perceptions and theory that we bring to bear in understanding them. To the extent that we grant legitimacy to more than one theory and its related formulation, they both can be right.

To return to the case of Sharon and the two formulations based on IDT and IRT perspectives: From the standpoint of coherence theory there are even more formulations that are possible and that can be considered legitimate. The case excerpts and Sharon's background described by Westerman and Critchfield et al. bring to mind the work of Weiss and Sampson on control-mastery theory (Weiss \& Sampson, 1986). Their fourfold scheme used in formulating cases includes items pertaining to patient goals, obstructions to these goals (i.e., pathological beliefs), tests that the patient might pose for the therapist (for example, whether the therapist responds in the dysfunctional way that a parent did) and insights to be acquired. The underlying theory stressed is the ubiquity of separation guilt — namely the difficulty people have in separating from others because they fear they would harm them if they did, which is a pathogenic belief stemming from childhood. Those elements are present in this case in so far as Sharon's father made it clear that her separating from him was very hurtful to him, generating guilt on her part. We can then posit that, in a similar manner, Sharon is worried about harming her ex-boyfriend, Jeff, which draws her back to him. 
But that is only one further possibility. From an object relations perspective, the issue is not separation guilt but separation anxiety — namely dependency issues, as Westerman and Critchfield et al. recognize. This is a different dynamic than separation guilt and would lead to different interventions.

If we were operating within a Freudian framework, we could also make a case for Sharon achieving an Oedipal victory, leaving her feeling guilty over winning the Oedipal competition with her mother leading to another form of guilt that keeps her from staying with Jeff. (This is quite different from the issue of excessive dependency). In support of this formulation, the reader may note that Sharon is very close to father, is his "little girl" and that he has poor boundaries, often confiding in Sharon about his marriage. In brief, there are several plausible but different ways to understand Sharon's problems, and all can be considered truthful within a narrative or pluralistic framework.

This brings us to consider a third theory of truth, known as pragmatic, which stands alongside the correspondence and coherence theories. According to William James, pragmatism

... asks its usual question. "Grant(ing) an idea or belief to be true," it says, "what concrete difference will its being true make in anyone's actual life? How will the truth be realized? What experiences will be different from those which would obtain if the belief were false? What, in short, is the truth's cash-value in experiential terms?" (p. 77).

How does this third theory of truth pertain to our dilemma of discerning the truth-value of the several different possible formulations of the case of Sharon? In the 1980's I directed a research group consisting of students from Rutgers' $\mathrm{PhD}$ and PsyD clinical programs. Being curious about the dilemma of the veracity of multiple case formulations, we looked at the cases that were formulated by the Weiss and Sampson group, also known as the Mount Zion or San Francisco Psychotherapy Group, and found ourselves to be in disagreement with them on the nature of the central dynamics. Where the Mount Zion group saw, in accordance with the tenets of Weiss and Sampson's control-mastery theory, instances of survivor and separation guilt that prevented patients from achieving independence, we saw issues of separation anxiety and immature dependency wishes in accordance with Fairbairn's (1946) object relations theory. That is, they understood these patients as concerned primarily about harming others with whom they were entangled in relationships whereas we perceived them as overly needy of these others.

This suggested a study: Is the Mt. Zion Plan Formulation Method transportable to another setting in which investigators are not wedded to control-mastery theory? The Rutgers and Mt. Zion groups selected two cases for study, one from the Mt. Zion archive of audio recorded and transcribed cases and one from the Rutgers archive, and we each created Plan Formulations according to their fourfold scheme. We were able to rate the Plan items reliably but each group endorsed very different plans. The Plan created by the Mt. Zion group reflected its cognitivedynamic theoretical emphasis, and the Rutgers Plan reflected our object relations emphasis (Collins \& Messer, 1991). The next step was to measure the extent to which therapist interventions compatible with each Plan were able to predict patient progress. In other words, using a pragmatic truth criterion, we asked which plan delivered the goods or, in James's words, had "cash value". 
Therapist statements were then scored on the Mt. Zion's Plan Compatibility of Intervention Scale, which measured how compatible the statement was with the Plan. Turning to the patient variable, our research group created a scale, the Rutgers Psychotherapy Progress and Stagnation Scale, which included areas such as exploration of significant material, development of insight, focus on the self, and emotional experiencing (Holland, Roberts \& Messer, 1998). The question we posed was, "Could patient progress or stagnation be predicted from compatibility of therapist interventions with one or both of these plans?" In other words, is one of the plans more suited to these patients? Making therapeutic progress is the pragmatic payoff referred to above.

We then compared the ability of plan compatibility of interventions--based on either Fairbairn's object relations theory or on Mt. Zion's cognitive-dynamic theory--to predict patient progress in three phases of these brief dynamic therapies--beginning, middle, and termination phase-because this is often how brief dynamic therapy is conceptualized. The pattern of correlations across the three phases was quite clear: The compatibility of therapist interventions with the Rutgers object relations plan correlated positively in five of the six instances (three phases for each of two patients), whereas the Mt. Zion interventions correlated negatively in five of the six instances, three of them significantly (Messer, Tishby \& Spillman, 1992). Stated differently, compatibility with the object relations Plan was associated with patient progress, but compatibility of interventions with the Mt. Zion cognitive-dynamic Plan predicted stagnation.

If we were to judge, based on this one study (which, of course is not sufficient especially given possible researcher allegiance effects), it appears that not any focus or formulation will do; the results point to there being more and less useful ways of formulating a case. However, we don't know just how widely these findings might generalize. Nor do we know whether a specific outlook, such as Fairbairn's object relations theory, is generally more fitting than other approaches, such as Weiss and Sampson's cognitive-dynamic theory, or if, as we suspect, it depends on the nature of the specific case (Messer \& McCann, 2005). Might the same be true of the pragmatic truth-value of IDT and IRT in formulating cases and predicting which therapist interventions would be most salutary?

What I propose to Westerman and Critchfield et al., is that they conduct a similar comparative study, if one such is not already underway, in which they look at how well therapist interventions that follow from each of their theories and formulations predict patient progresswhether in the case of Sharon or in other cases. This would be an empirical and pragmatic way of continuing the dialogue about correspondence vs. coherence vs. pragmatic theories of truth regarding clinical cases and give us a way of adjudicating between plausible, but different, theories and the interventions that follow from them. 


\section{REFERENCES}

Collins, W. D., \& Messer, S. B. (1991). Extending the Plan Formulation Method to an object relations perspective: Reliability, stability and adaptability. Psychological Assessment: A Journal of Consulting and Clinical Psychology, 3, 75-81.

Critchfield, K.L., Dobner-Pereira, J., \& Stucker, E. (2021a). The case of Sharon considered from the vantage point of Interpersonal Reconstructive Therapy.

Pragmatic Case Studies in Psychotherapy, 17 (1), Article 4, 42-62. Available: http://pcsp.libraries.rutgers.edu/

Holland, S. J., Roberts, N.E., \& Messer, S. B. (1998). The reliability and validity of the Rutgers Psychotherapy Progress Scale. Psychotherapy Research, 8, 104-110.

James, W. (1907). Pragmatism's conception of truth. Lecture 6 in Pragmatism: A new name for some old ways of thinking (pp. 76-91). New York: Longman Green Co.

Messer, S. B., \& McCann, L. (2005). Research perspectives on the case study: single-case method. In J. S. Auerbach, K. N. Levy, \& C. E. Schaffer (Eds.), Relatedness, selfdefinition and mental representation: Essays in honor of Sidney J. Blatt (pp. 222-237). NY: Routledge.

Messer, S. B., Tishby O., \& Spillman, A. (1992). Taking context seriously in psychotherapy research: Relating therapist interventions to patient progress in brief psychodynamic therapy. Journal of Consulting and Clinical Psychology, 60, 678-688.

Spence. (1982). Narrative truth and historical truth. New York: Norton.

Weiss, J., Sampson, H., \& the Mount Zion Psychotherapy Research Group (Eds.) (1986). The psychoanalytic process: Theory, clinical observation, and empirical research. New York: Guilford Press.

Westerman, M.A. (2021a). The case of Sharon considered from the vantage point of nterpersonal Defense Theory. Pragmatic Case Studies in Psychotherapy, 17 (1), Article 3, 19-41. Available: http://pcsp.libraries.rutgers.edu/ 